Article

\title{
Synthesis of Ferrocenyl-Substituted Organochalcogenyldichlorogermanes
}

\author{
Takahiro Sasamori ${ }^{1, *\left(\mathbb{D}, \text {, Yuko Suzuki }^{2}, \text { Koh Sugamata }^{3} \text {, Tomohiro Sugahara }\right.}{ }^{2}$ \\ and Norihiro Tokitoh ${ }^{2}$ \\ 1 Graduate School of Natural Sciences, Nagoya City University, Yamanohata 1, Mizuho-cho, Mizuho-ku, \\ Nagoya, Aichi 467-8501, Japan \\ 2 Institute for Chemical Research, Gokasho, Uji, Kyoto 611-0011, Japan; \\ y_suzuki@boc.kuicr.kyoto-u.ac.jp (Y.S.); sugahara@boc.kuicr.kyoto-u.ac.jp (T.S.); \\ tokitoh@boc.kuicr.kyoto-u.ac.jp (N.T.) \\ 3 Department of Chemistry, College of Science, Rikkyo University, 3-34-1 Nishi-Ikebukuro, Toshima-ku, \\ Tokyo 171-8501, Japan; sugamata@rikkyo.ac.jp \\ * Correspondence: sasamori@nsc.nagoya-cu.ac.jp; Tel.: +81-52-872-5820
}

Received: 13 June 2018; Accepted: 9 July 2018; Published: 11 July 2018

check for updates

\begin{abstract}
Reaction of the isolable ferrocenyldichlorogermyl anion, $\mathrm{Fc}^{*} \mathrm{GeCl}_{2}{ }^{-}\left(\mathrm{Fc}^{*}=2,5\right.$-bis(3,5-di$t$-butylphenyl)-1-ferrocenyl), with the isolable chalcogenenyl halides resulted in the formation of the corresponding organochalcogenyldichlorogermanes that were structurally characterized. Thus, it was demonstrated the use of sterically demanding ferrocenyl groups allowed isolating stable crystalline organochalcogenyldichlorogermanes.
\end{abstract}

Keywords: ferrocene; steric protection; germanium; selenide; telluride; selenenylchloride; tellurenylchloride

\section{Introduction}

Germanium chalcogenides are interesting chemical species for optoelectronic modules due to the appropriate combination between the electron-accepting element $\mathrm{Ge}$ and an electron-donating element, such as Se or Te, because the size and energy levels of frontier orbitals should be close to each other (4p and $4 p / 5 p)[1,2]$. Therefore, organogermanium species that bear a chalcogen (Ch) moiety should be able to serve as building blocks for organic-inorganic hybrid materials that contain a $\mathrm{Ge}-\mathrm{Ch}$ bond. Given that the Ge-Ch bond is redox-active, metallocenyl-substituted germanium chalcogenides could be promising prospective building blocks for such Ge-Ch hybrid materials. Although the appropriate molecular design for such building blocks should be $\mathrm{Mc}-\mathrm{GeX}_{2}-\mathrm{ChR}$ ( $\mathrm{Mc}=$ metallocenyl; $\mathrm{R}=$ organic substituent; $\mathrm{X}=$ leaving group), it is generally difficult to isolate such species on account of the lability due to facile hydrolysis of the $\mathrm{Ge}-\mathrm{Ch}$ and $\mathrm{Ge}-\mathrm{X}$ bonds. In addition, a conceivable synthetic strategy such as the nucleophilic substitution of the $\mathrm{RCh}$ moiety toward $\mathrm{Mc}-\mathrm{GeCl}_{3}$, would most likely not be selective, i.e., two- and three-fold substitution could easily occur (Scheme 1). In this paper, we report a solution to this problem by using a method that is based on kinetic control using a bulky ferrocenyl group. We have already prepared sterically demanding ferrocenyl groups [3-6] that are able to stabilize anionic species that bear a halogen group due to multi-hydrogen bonding [7]. The use of the sterically demanding ferrocenyl group $\mathrm{Fc}^{*}$ (2,5-bis(3,5-di-t-butylphenyl)-1-ferrocenyl) enabled us to isolate the dichlorogermyl anion $\left[\mathrm{Fc}^{*} \mathrm{GeCl}_{2}\right]^{-}$, which was identified as a chlorogermylenoid [7]. Subsequently, we speculated that the germylenoid could not only work as an electrophile but also as a nucleophile towards chalcogens, even in the presence of two halogen atoms. Herein, we demonstrate the reactions of a stable germylenoid with selenenyl and tellurenyl chlorides, which affords stable 
dichlorochalcogenagermanes that bear a bulky ferrocenyl group. These dichlorochalcogenagermanes represent promising prospective building blocks for organogermanium chalcogenides.

\section{Concept for the molecular design}
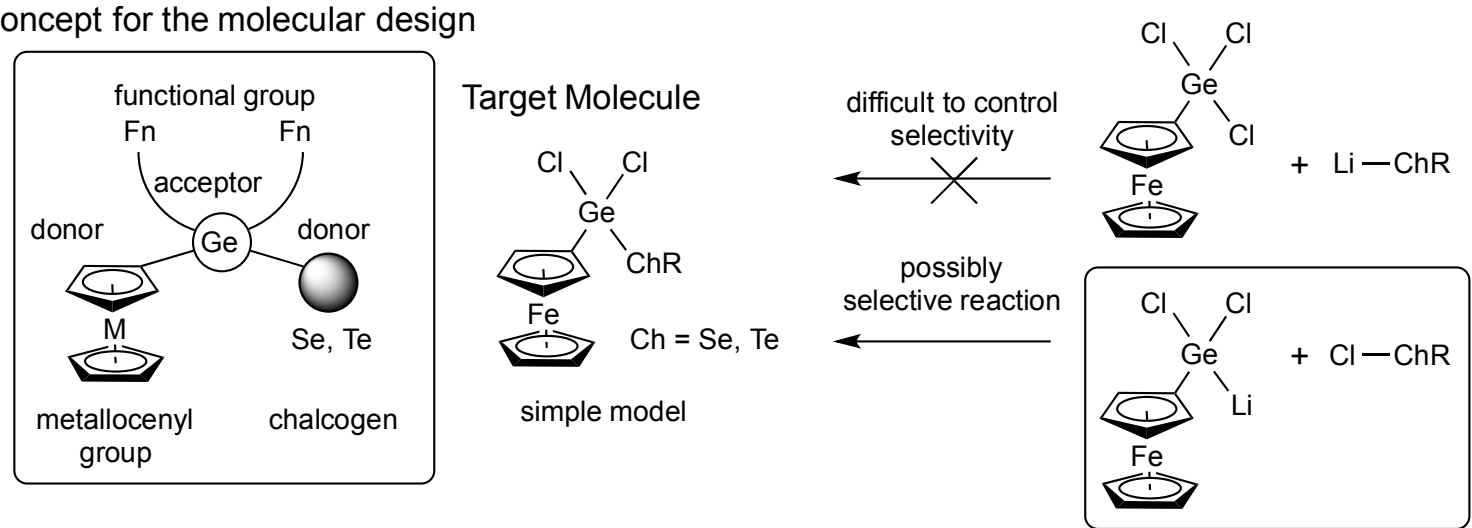

Scheme 1. Schematic illustration of the synthetic strategy applied in this study for the generation of ferrocenyl-substituted chalcogenyldichlorogermanes.

\section{Results and Discussions}

To isolate stable chalcogenenyl halides, it is necessary to introduce sterically demanding substituents on the $\mathrm{Ch}$ atom [8-10]. We have decided to use the 9-triptycyl (Trp) group as a steric protection group, as the simple synthesis of the corresponding dichalcogenides $(\mathbf{1 a}, \mathbf{b})$ has already been reported [11-13]. The treatment of an ether solution of TrpSeSeTrp (1a) [11] with $\mathrm{SO}_{2} \mathrm{Cl}_{2}$ at room temperature afforded the corresponding selenenyl chloride, $\operatorname{TrpSeCl}(\mathbf{2 a})$, as a stable crystalline compound (Scheme 2). In a similar fashion, $\operatorname{TrpTeCl}(\mathbf{2 b})$ was obtained from the reaction of TrpTeTeTrp (1b) $[12,13]$ with $\mathrm{SO}_{2} \mathrm{Cl}_{2}$. The molecular structures of $\operatorname{TrpSeCl}(\mathbf{2 a})$ and $\operatorname{TrpTeCl}(\mathbf{2} \mathbf{b})$ were unambiguously determined by $\mathrm{X}$-ray diffraction (XRD) analyses, which delivered $\mathrm{C}-\mathrm{Ch}-\mathrm{Cl}$ angles of 99.93(6) ${ }^{\circ}(\mathrm{Ch}=\mathrm{Se})$ and $96.38(9)^{\circ}(\mathrm{Ch}=\mathrm{Te})$, as well as $\mathrm{Ch}-\mathrm{Cl}$ bond lengths of 2.1860(7) $\AA$ ( $\left.\mathrm{Ch}=\mathrm{Se}\right)$ and 2.348(1) $\AA(\mathrm{Ch}=\mathrm{Te})$. These structural parameters are similar to those of previously reported stable selenenyl- and tellurenyl-chlorides [8-10], indicating negligible electronic perturbations from the Trp group toward the $\mathrm{Ch}-\mathrm{Cl}$ moieties. The packing structures of $\mathbf{2 a}$ and $\mathbf{2} \mathbf{b}$ suggest that these compounds are monomeric in the crystalline state (Figure 1). As only $\mathbf{2 a}$ contains one molecule of benzene per unit cell, the packing structures and space groups of $\mathbf{2} \mathbf{a}$ and $\mathbf{2 b}$ are different. While $\mathbf{2} \mathbf{b}$ exhibits head-to-tail-type interactions, 2a shows head-to-head-type interactions, albeit that the intramolecular interactions should be negligible due to the long intramolecular $\mathrm{Ch} \cdots \mathrm{Ch}, \mathrm{Ch} \cdots \mathrm{Cl}$, and $\mathrm{Cl} \cdots \mathrm{Cl}$ distances. In addition, the ${ }^{77} \mathrm{Se}(907 \mathrm{ppm})$ and ${ }^{125} \mathrm{Te}$ NMR chemical shifts (1756 ppm) are consistent with those of previously reported monomeric chalcogenenylhalides [8-10].
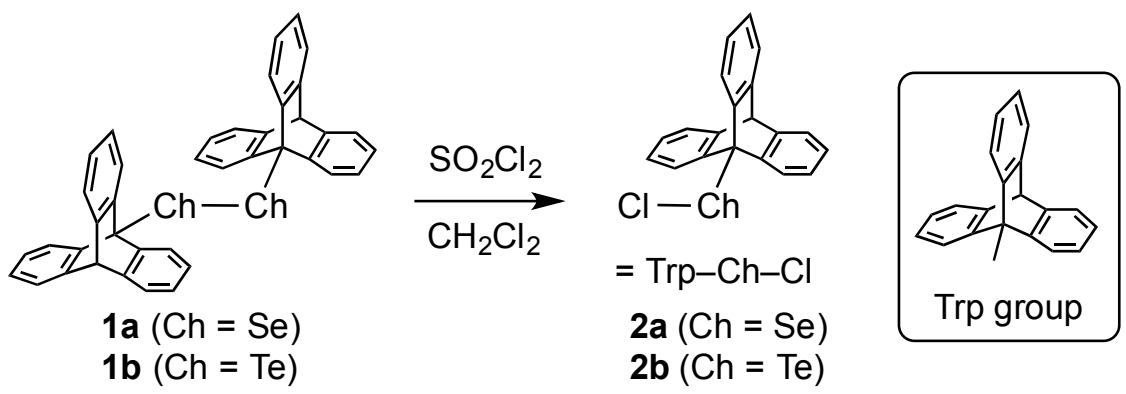

Scheme 2. Synthesis of stable chalcogenylchlorides 2. 
(A) $2 a$

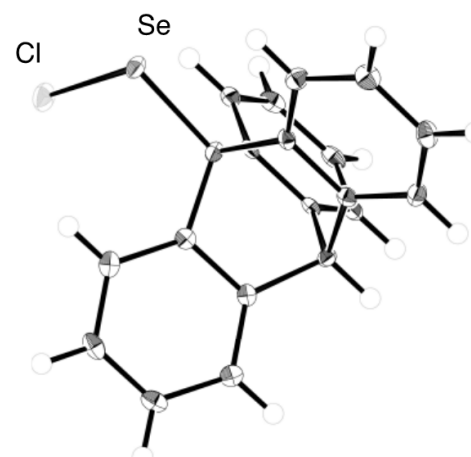

(B) $\mathbf{2 b}$

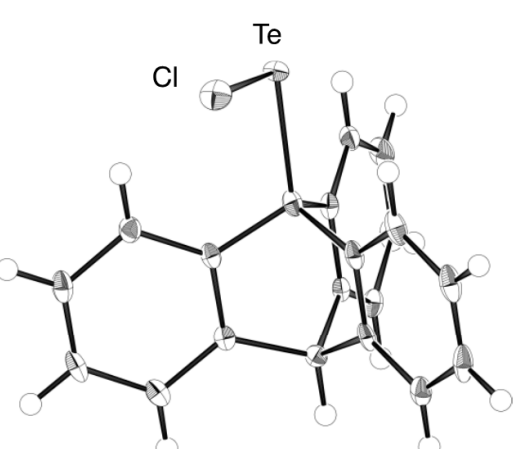

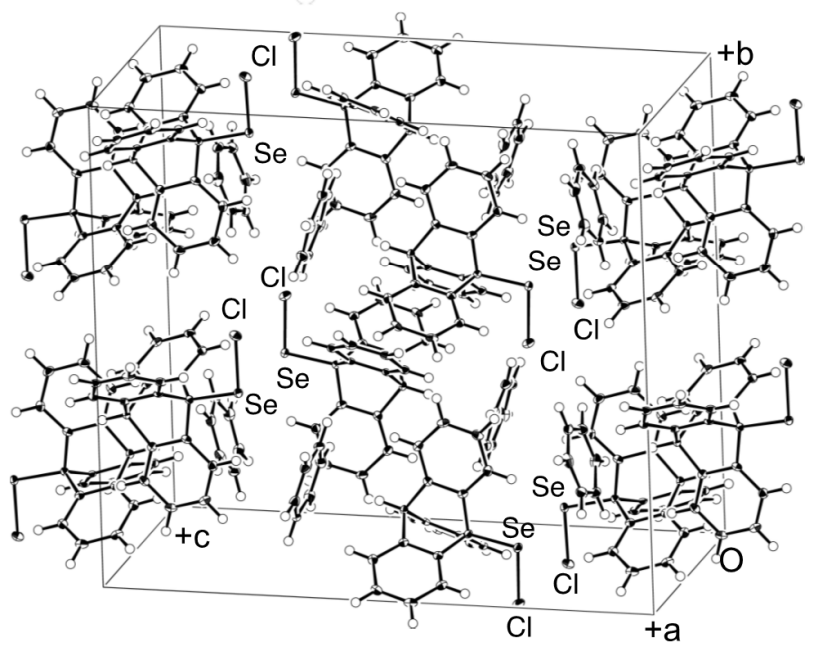

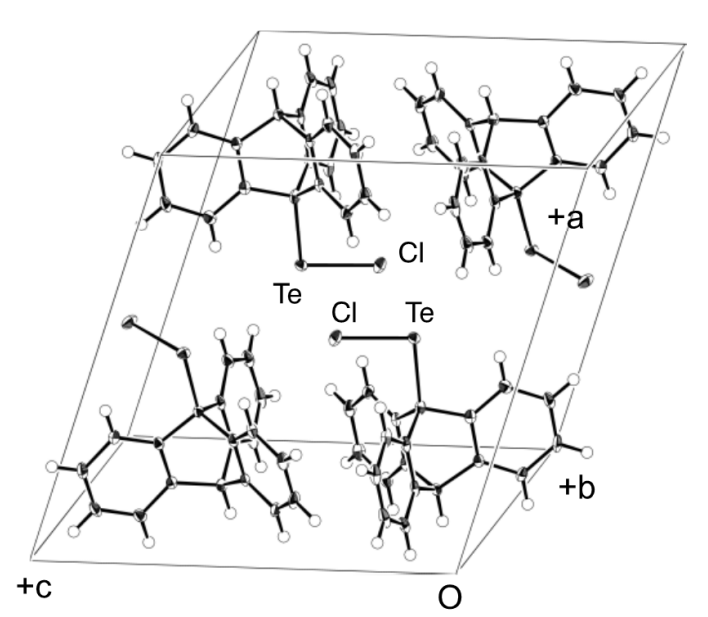

Figure 1. Molecular structures (ORTEP drawing at 50\% probability) and crystal packing of (A) [2a-benzene] and (B) $\mathbf{2 b}$ with atomic displacement parameters set at $50 \%$ probability. Selected bond lengths $(\AA)$ and angles $\left(^{\circ}\right)$ : (A) Se-Cl, 2.1860(7); Se-C, 1.965(2); C-Se-Cl, 99.93(6), (B) Te-Cl, 2.348(1);

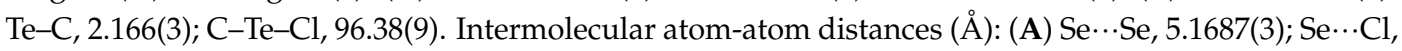
5.5440(6); $\mathrm{Cl} \cdots \mathrm{Cl}, 5.6875(6),($ B) $\mathrm{Te} \cdots \mathrm{Te}, 5.3089(7) ; \mathrm{Te} \cdots \mathrm{Cl}, 4.395(1) ; \mathrm{Cl} \cdots \mathrm{Cl}, 4.634(1)$.

The sterically hindered germylenoid $\mathrm{Fc}^{*} \mathrm{GeCl}_{2} \mathrm{Li}$ (4) was prepared according to literature procedures [5] from the reaction of the isolable lithioferrocene dimer 3 with $\mathrm{GeCl}_{2}$.(dioxane). Subsequently, $\mathbf{4}$ was treated with the isolated chalcogenenylchlorides $\mathbf{2 a}$ or $\mathbf{2 b}$ in toluene at room temperature. The NMR spectra of the crude reaction mixtures suggested the predominant formation of the expected products $(\mathbf{5 a}, \mathbf{b})$ together with small amounts of the by-product $\mathrm{Fc}^{*}{ }_{2} \mathrm{GeCl}_{2}$ (6) [14] in both cases $(5: 6=8: 1$ for $\mathrm{Ch}=\mathrm{Se} ; \mathbf{5 : 6}=21: 1$ for $\mathrm{Ch}=\mathrm{Te}$ ). The purification processes, including GPC separation and recrystallization from hexane, afforded the stable chalcogenyldichlorogermanes $\mathbf{5 a}$ and $\mathbf{5 b}$ in $41 \%$ and $58 \%$ isolated yields, respectively, together with the corresponding bis(ferrocenyl)dichlorogermane in both cases ( $31 \%$ for $\mathrm{Ch}=\mathrm{Se} ; 17 \%$ for $\mathrm{Ch}=\mathrm{Te}$ ) (Scheme 3). Although the formation mechanism for 6 cannot be explained unequivocally at present, the oxidation of germylenoid 4 by chalcogenenylchloride 2 could initiate the unexpected formation of 6 . 

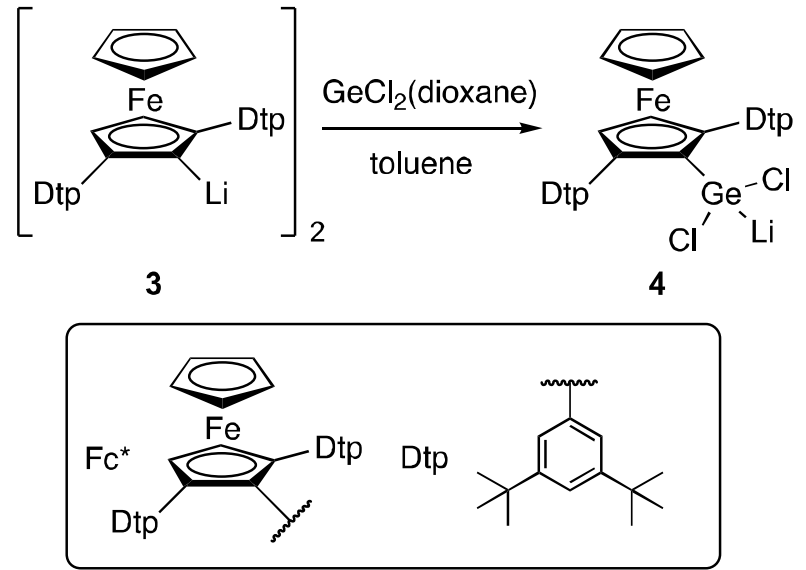

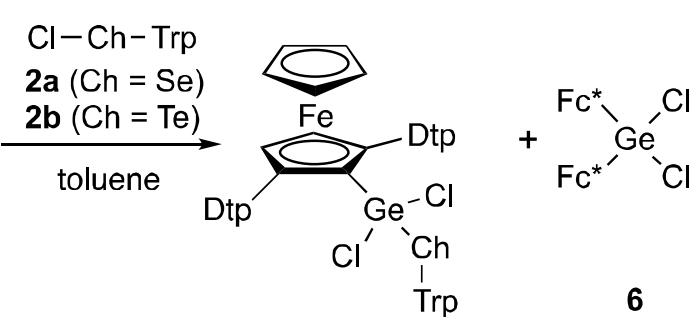

$5 \mathbf{a}(\mathrm{Ch}=\mathrm{Se})$

$\mathbf{5 b}(\mathrm{Ch}=\mathrm{Te})$

Scheme 3. Synthesis of chalcogenyldichlorogermanes $\mathbf{5 a , b}$.

The molecular structures of chalcogenyldichlorogermanes $\mathbf{5 a}$ and $\mathbf{5 b}$ were determined by single-crystal XRD analyses (Figure 2). Unexpectedly, their geometries are different, i.e., the $\mathrm{Ch}$ moiety in $\mathbf{5 a}(\mathrm{Ch}=\mathrm{Se})$ is spatially removed from the Fe atom or located "outside of the ferrocenyl unit" (Form A), while that of $\mathbf{5 b}(\mathrm{Ch}=\mathrm{Te})$ is close to the Fe atom or oriented "toward the ferrocenyl unit" (Form B). In both cases, the two energy minima, i.e., Form A and B, were identified by theoretical calculations at the M062x/6-311G(3d) $(\mathrm{Ge}, \mathrm{Cl}, \mathrm{Fe}) /$ 6-31G(d) (C, H) / SDD (Se, Te) level of theory [15]. The optimized structures of $\mathbf{5 a}$-Form $\mathbf{A}$ and $\mathbf{5 b}$-Form $\mathbf{B}$ were in good agreement with those experimentally obtained from the XRD analyses (Table 1). Although the thermodynamic energies of Form A and Form B are similar in both cases, 5a-Form A and 5b-Form B are more stable than their imaginary forms, i.e., 5 a-Form $\mathbf{B}(+0.33 \mathrm{kcal} / \mathrm{mol})$ and $\mathbf{5 b}$-Form $\mathbf{A}(+1.38 \mathrm{kcal} / \mathrm{mol})$, which supports the experimental results. At present, however, we do not have a reasonable explanation regarding the energy differences between Form A and Form B.

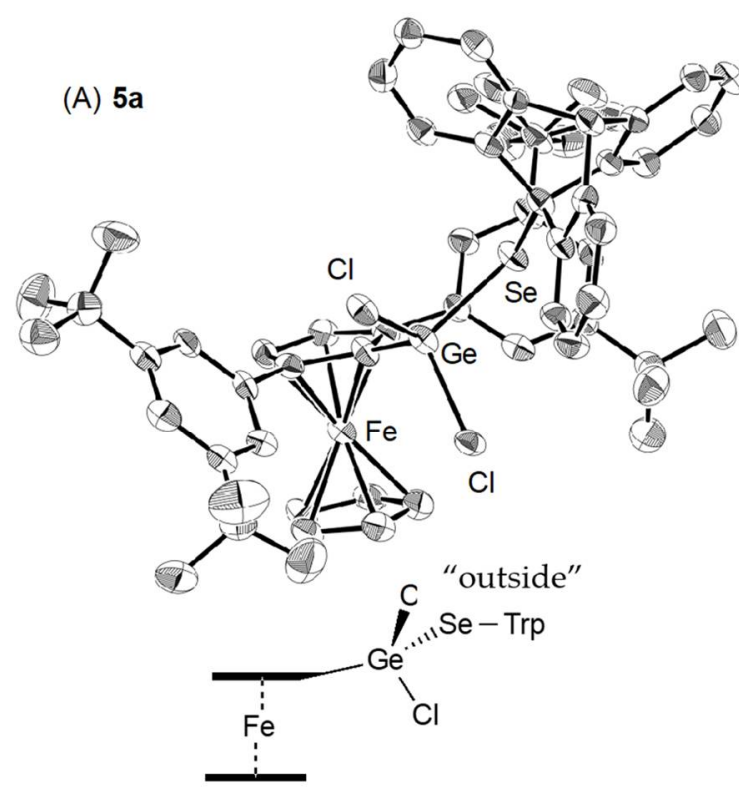

Form A

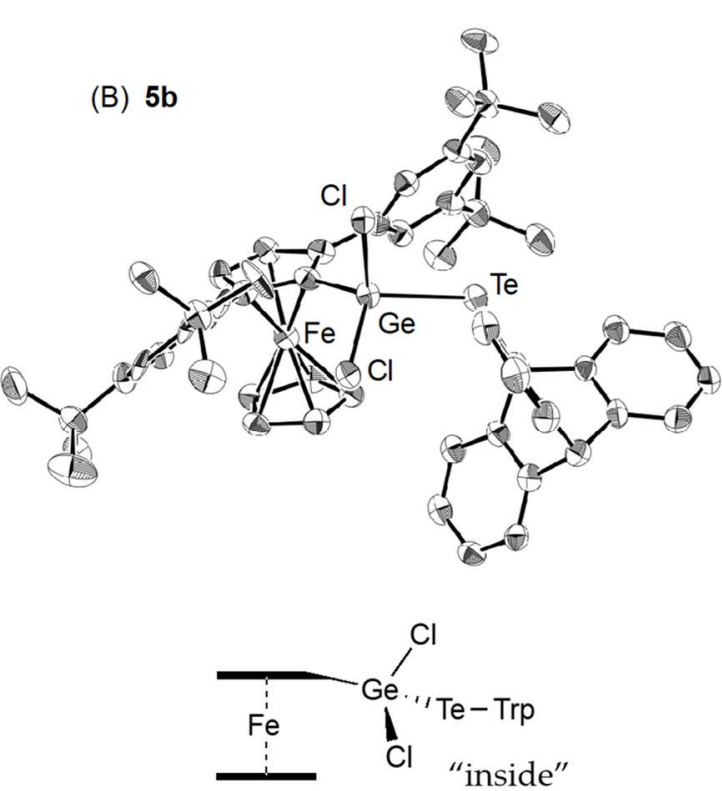

Form B

Figure 2. Molecular structures of (A) $5 \mathbf{a}$ and (B) $5 \mathbf{b}$ with atomic displacement parameters set at $50 \%$ probability. All hydrogen atoms and solvent molecules were omitted for clarity and only selected atoms are labeled. 
Table 1. Selected structural parameters for 5a-Form A and 5b-Form B (observed: XRD analysis) together with the corresponding theoretical (calculated) values for 5a-Form A, 5a-Form B, 5b-Form A, and 5b-Form $\mathbf{B}$ that were optimized at the M062x/6-311G(3d) $(\mathrm{Ge}, \mathrm{Cl}, \mathrm{Fe}) / 6-31 \mathrm{G}(\mathrm{d})(\mathrm{C}, \mathrm{H}) / \mathrm{SDD}$ (Se, Te) level of theory.

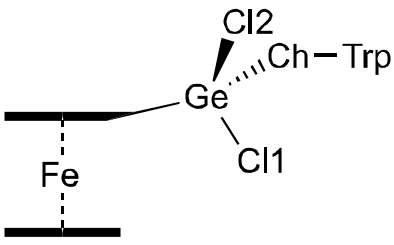

Form A

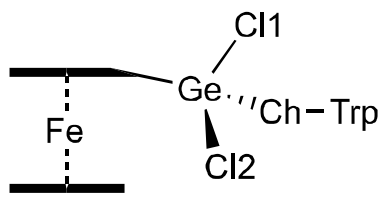

Form B

\begin{tabular}{|c|c|c|c|c|c|c|}
\hline Distance/Å & $\begin{array}{c}\text { 5a }(\mathrm{Ch}=\mathrm{Se}) \\
\text { Form A } \\
\text { Observed }\end{array}$ & $\begin{array}{c}5 a(C h=S e) \\
\text { Form A } \\
\text { Calculated }\end{array}$ & $\begin{array}{c}5 a(C h=S e) \\
\text { Form B } \\
\text { Calculated }\end{array}$ & $\begin{array}{c}5 b(\mathrm{Ch}=\mathrm{Te}) \\
\text { Form A } \\
\text { Calculated }\end{array}$ & $\begin{array}{c}5 b(C h=T e) \\
\text { Form B } \\
\text { Calculated }\end{array}$ & $\begin{array}{c}5 b(\mathrm{Ch}=\mathrm{Te}) \\
\text { Form B } \\
\text { Observed }\end{array}$ \\
\hline$C(C p)-G e$ & $1.926(6)$ & 1.9289 & 1.9290 & 1.9308 & 1.9309 & $1.927(8)$ \\
\hline $\mathrm{Ge}-\mathrm{Ch}$ & $2.3474(9)$ & 2.3870 & 2.3904 & 2.5878 & 2.5869 & $2.5489(8)$ \\
\hline $\mathrm{Ge}-\mathrm{Cl} 1$ & $2.209(2)$ & 2.1873 & 2.2018 & 2.1979 & 2.2081 & $2.212(2)$ \\
\hline $\mathrm{Ge}-\mathrm{Cl} 2$ & $2.164(2)$ & 2.1577 & 2.1561 & 2.1609 & 2.1624 & $2.164(2)$ \\
\hline $\mathrm{Fe} \cdots \mathrm{Ge}$ & $3.696(1)$ & 3.6587 & 3.5460 & 3.7326 & 3.5252 & $3.505(2)$ \\
\hline $\mathrm{Fe} \cdots \mathrm{Cl} 1$ & $4.194(2)$ & 4.0287 & 5.3396 & 4.2108 & 5.3303 & $5.305(3)$ \\
\hline $\mathrm{Fe} \cdots \mathrm{Cl} 2$ & $5.176(2)$ & 5.1614 & 4.3337 & 5.1220 & 4.2763 & $4.317(2)$ \\
\hline $\mathrm{Fe} \cdots \mathrm{Ch}$ & $5.229(1)$ & 5.3217 & 4.6049 & 5.6007 & 4.7724 & $4.761(1)$ \\
\hline \multicolumn{7}{|l|}{ Angles $/^{\circ}$} \\
\hline $\mathrm{Cl} 1-\mathrm{Ge}-\mathrm{Cl} 2$ & $104.06(7)$ & 105.85 & 105.68 & 102.93 & 105.82 & 104.51(8) \\
\hline $\mathrm{Cl1}-\mathrm{Ge}-\mathrm{Ch}$ & $110.59(5)$ & 103.47 & 108.33 & 108.95 & 108.17 & $106.62(6)$ \\
\hline $\mathrm{Cl} 2-\mathrm{Ge}-\mathrm{Ch}$ & $110.92(5)$ & 110.60 & 110.15 & 110.48 & 109.03 & $110.32(6)$ \\
\hline
\end{tabular}

The experimentally observed and theoretically optimized structural parameters are summarized in Table 1. In both cases, i.e., Form A and Form B, one of the two chlorine atoms (Cl1) is vertically oriented toward the $\mathrm{Cp}$ plane of the ferrocenyl unit. In both cases, the $\mathrm{Ge}-\mathrm{Cl} 1$ bonds are slightly longer than the $\mathrm{Ge}-\mathrm{Cl} 2$ bonds, indicating an orbital interaction between the $\sigma^{*}(\mathrm{Ge}-\mathrm{Cl} 1)$ orbital and lone pairs on the $\mathrm{Cl} 2$ and $\mathrm{Ch}$ (Se or Te) atoms. Indeed, the NBO (Natural Bond Orbitals) calculations [16] suggested effective $\pi(\mathrm{Cp}) \rightarrow \sigma^{*}(\mathrm{Ge}-\mathrm{Cl} 1), \mathrm{LP}(\mathrm{Cl} 2) \rightarrow \sigma^{*}(\mathrm{Ge}-\mathrm{Cl} 1)$, and $\mathrm{LP}(\mathrm{Ch}) \rightarrow \sigma^{*}(\mathrm{Ge}-\mathrm{Cl} 1)$ interactions, all of which would result in an elongation of the Ge-Cl1 bond. These results indicate that the $\mathrm{Ge}-\mathrm{Ch}$ and $\mathrm{Ge}-\mathrm{Cl} 2$ bonds would be maintained, even after the functionalization of the $\mathrm{Ge}-\mathrm{Cl} 1$ moiety, given that the $\mathrm{Ge}-\mathrm{Ch}$ and $\mathrm{Ge}-\mathrm{Cl} 2$ bonds should strengthen rather than weaken the $\mathrm{Ge}-\mathrm{Cl} 1$ bond. Thus, $\mathbf{5 a}$ and $\mathbf{5 b}$ should be suitable as potential building blocks for ferrocenyl-substituted germanium chalcogenides.

\section{Materials and Methods}

\subsection{General Information}

All manipulations were carried out under an argon atmosphere using either Schlenk-line or glovebox techniques. Solvents were purified using the Ultimate Solvent System (Glass Contour Company, CA, USA) [17]. ${ }^{1} \mathrm{H},{ }^{13} \mathrm{C},{ }^{77} \mathrm{Se}$, and ${ }^{125} \mathrm{Te}$ NMR spectra were measured on JEOL 300 or $400 \mathrm{MHz}$ spectrometers (JEOL, Tokyo, Japan). Signals arising from residual $\mathrm{C}_{6} \mathrm{D}_{5} \mathrm{H}(7.15 \mathrm{ppm})$ in $\mathrm{C}_{6} \mathrm{D}_{6}$ and $\mathrm{CHCl}_{3}(7.25 \mathrm{ppm})$ in $\mathrm{CDCl}_{3}$ were used as an internal standard for the ${ }^{1} \mathrm{H}$ NMR spectra, while signals of $\mathrm{C}_{6} \mathrm{D}_{6}(128.0 \mathrm{ppm})$ and $\mathrm{CDCl}_{3}(77.0 \mathrm{ppm})$ where used to reference the ${ }^{13} \mathrm{C}$ NMR spectra. PhSeSePh (460 ppm) and PhTeTePh (450 ppm) were used as external standards for the ${ }^{77} \mathrm{Se}$ and ${ }^{125} \mathrm{Te}$ NMR spectra. High-resolution mass spectra (HRMS) were measured on a Bruker micrOTOF 
focus-Kci mass spectrometer (DART) (Bruker Japan K.K. Daltonics Division, Kanagawa, Japan) or a JEOL JMS-700 spectrometer (FAB) (JEOL, Tokyo, Japan). All melting points were determined on a Büchi Melting Point Apparatus M-565 (Büchi Japan, Tokyo, Japan) and are uncorrected. Elemental analyses were carried out at the Microanalytical Laboratory, Institute for Chemical Research, Kyoto University. Dichalcogenides $\mathbf{1 a}$ and $\mathbf{1 b}$ [11-13] as well as chlorogermylenoid $\mathbf{4}$ [7] were prepared according to literature procedures.

\subsection{Experimental Details}

\subsubsection{Synthesis of Selenenylchloride 2a}

A suspension of TrpSeSeTrp (1a, $665 \mathrm{mg}, 1.00 \mathrm{mmol})$ in $\mathrm{CH}_{2} \mathrm{Cl}_{2}(10 \mathrm{~mL})$ was treated with $\mathrm{SO}_{2} \mathrm{Cl}_{2}$ $(135 \mathrm{mg}, 1.00 \mathrm{mmol}$ ) at room temperature for $1 \mathrm{~h}$. After the removal of all volatiles, the residue was recrystallized from $\mathrm{CH}_{2} \mathrm{Cl}_{2}$ at room temperature to give $2 \mathbf{a}$ as orange crystals in $51 \%$ yield ( $376 \mathrm{mg}$, $1.02 \mathrm{mmol})$. Data for 2a: orange crystals, m.p. $=212.2{ }^{\circ} \mathrm{C}\left(\mathrm{dec}\right.$.); ${ }^{1} \mathrm{H} \mathrm{NMR}\left(400 \mathrm{MHz}, \mathrm{CDCl}_{3}, 298 \mathrm{~K}\right)$ : $\delta(\mathrm{ppm}) 5.41(\mathrm{~s}, 1 \mathrm{H}), 7.00-7.10(\mathrm{~m}, 6 \mathrm{H}), 7.40-7.42(\mathrm{~m}, 3 \mathrm{H}), 7.50-7.52(\mathrm{~m}, 3 \mathrm{H}) ;{ }^{13} \mathrm{C} \mathrm{NMR}(100 \mathrm{MHz}$, $\left.\mathrm{CDCl}_{3}, 298 \mathrm{~K}\right): \delta(\mathrm{ppm}) 54.1$ (d), 64.3 (s), 123.5 (d), 123.7 (d), 125.3 (d), 126.1 (d), 143.7 (s), 145.4 (d); ${ }^{77} \mathrm{Se}$ NMR (76 MHz, $\mathrm{CDCl}_{3}, 298 \mathrm{~K}$ ): $\delta$ (ppm) 907; Anal. Calcd. for $\mathrm{C}_{20} \mathrm{H}_{13} \mathrm{ClSe}: \mathrm{C}, 65.32 ; \mathrm{H}, 3.56$. Found: $\mathrm{C}$, 65.01; H, 3.73. MS (DART-TOF, positive mode): $m / z$ Calcd. for $\mathrm{C}_{20} \mathrm{H}_{13}{ }^{35} \mathrm{Cl}^{80} \mathrm{Se} 367.9871$ ([M] ${ }^{+}$), found $367.9886\left([\mathrm{M}]^{+}\right)$.

\subsubsection{Synthesis of Tellurenylchloride $\mathbf{2} \mathbf{b}$}

A suspension of TrpTeTeTrp $\mathbf{1 b}(762 \mathrm{mg}, 1.00 \mathrm{mmol})$ in $\mathrm{CH}_{2} \mathrm{Cl}_{2}(10 \mathrm{~mL})$ was treated with $\mathrm{SO}_{2} \mathrm{Cl}_{2}$ $(135 \mathrm{mg}, 1.00 \mathrm{mmol}$ ) at room temperature for $1 \mathrm{~h}$. After the removal of all volatiles, the residue was recrystallized from $\mathrm{CH}_{2} \mathrm{Cl}_{2}$ /benzene at room temperature to give $\mathbf{2 b}$ as blue crystals in $57 \%$ yield (416 mg, $1.13 \mathrm{mmol})$. Data for $2 \mathbf{b}$ : blue crystals, m.p. $=228.1{ }^{\circ} \mathrm{C}$ (dec.); ${ }^{1} \mathrm{H}$ NMR $\left(400 \mathrm{MHz}, \mathrm{CDCl}_{3}\right.$, $298 \mathrm{~K}): \delta$ (ppm) 5.44 (s, 1H), 7.00-7.10 (m, 6H), 7.32-7.35 (m, 3H), 7.40-7.43 (m, 3H); ${ }^{13} \mathrm{C} \mathrm{NMR}(100 \mathrm{MHz}$, $\left.\mathrm{CDCl}_{3}, 298 \mathrm{~K}\right): \delta(\mathrm{ppm}) 54.5$ (d), 57.3 (s), 123.8 (d), 125.6 (d), 126.0 (d), 126.3 (d), 145.4 (s), 145.8 (d); ${ }^{125} \mathrm{Te}$ NMR (125 MHz, $\left.\mathrm{CDCl}_{3}, 298 \mathrm{~K}\right): \delta$ (ppm) 1756; Anal. Calcd. for $\mathrm{C}_{20} \mathrm{H}_{13} \mathrm{ClTe}$ C, 57.69; H, 3.15 . Found: C, 57.46; H, 3.14. MS (DART-TOF, positive mode): $m / z$ Calcd. for $\mathrm{C}_{20} \mathrm{H}_{13}{ }^{35} \mathrm{Cl}^{130} \mathrm{Te} 417.9768$ $\left([\mathrm{M}]^{+}\right)$, found $417.9733\left([\mathrm{M}]^{+}\right)$.

\subsubsection{Reaction of Chlorogermylenoid 4 with Selenenylchloride 2a}

A toluene solution $(3 \mathrm{~mL})$ of chlorogermylenoid $4(123.5 \mathrm{mg}, 0.173 \mathrm{mmol})$ was treated with $\operatorname{TrpSeCl}(\mathbf{2 a}, 64.8 \mathrm{mg}, 0.176 \mathrm{mmol})$ at room temperature. After stirring the reaction mixture for $3 \mathrm{~h}$, the solvent was removed under reduced pressure. The residue was extracted into toluene and filtered before the solvent was removed from the filtrate under reduced pressure. The residue was purified by high performance liquid chromatography (HPLC) (eluent: toluene) and recrystallization from hexane to give $5 \mathbf{a}$ as the main product in $41 \%$ yield $(73.7 \mathrm{mg}, 0.0710 \mathrm{mmol})$, and 6 ( $34.0 \mathrm{mg}, 0.0268 \mathrm{mmol}$, $31 \%)$. Data for 5a: orange crystals, m.p. $231{ }^{\circ} \mathrm{C}$ (dec.); ${ }^{1} \mathrm{H}$ NMR $\left(300 \mathrm{MHz}, \mathrm{C}_{6} \mathrm{D}_{6}\right.$, r.t.): $\delta$ (ppm) $1.40(\mathrm{~s}, 36 \mathrm{H}), 4.47(\mathrm{~s}, 5 \mathrm{H}), 4.72(\mathrm{~s}, 2 \mathrm{H}), 4.96(\mathrm{~s}, 1 \mathrm{H}), 6.67-6.72(\mathrm{~m}, 3 \mathrm{H}), 6.76-6.79(\mathrm{~m}, 3 \mathrm{H}), 6.99(\mathrm{~d}, 3 \mathrm{H}$, $J=7.1 \mathrm{~Hz}), 7.55(\mathrm{t}, 2 \mathrm{H}, J=1.7 \mathrm{~Hz}), 7.76(\mathrm{~d}, 3 \mathrm{H}, J=7.4 \mathrm{~Hz}), 7.91(\mathrm{~d}, 4 \mathrm{H}, J=1.7 \mathrm{~Hz}) ;{ }^{13} \mathrm{C} \mathrm{NMR}(75 \mathrm{MHz}$, $\left.\mathrm{C}_{6} \mathrm{D}_{6}, 298 \mathrm{~K}\right): \delta(\mathrm{ppm}) 31.77(\mathrm{q}), 35.22(\mathrm{~s}), 54.52(\mathrm{~d}), 66.94(\mathrm{~s}), 71.86(\mathrm{~d}), 73.06(\mathrm{~d}), 83.69(\mathrm{~s}), 96.62(\mathrm{~s})$, 122.30 (d), 123.20 (d), 124.91 (d), 125.28 (d), 125.89 (d), 126.13 (d), 136.92 (s), 145.07 (s), 146.01 (s), 151.02 (s); ${ }^{77} \mathrm{Se}$ NMR (57 MHz, $\mathrm{C}_{6} \mathrm{D}_{6}, 298 \mathrm{~K}$ ): $\delta$ (ppm) 168; MS (DART-TOF, positive mode): $\mathrm{m} / z$ Calcd. for $\mathrm{C}_{58} \mathrm{H}_{63}{ }^{37} \mathrm{Cl}_{2}{ }^{57} \mathrm{Fe}^{72} \mathrm{Ge}^{76} \mathrm{Se} 1038.2068\left([\mathrm{M}+\mathrm{H}]^{+}\right)$, found $1038.2084\left([\mathrm{M}+\mathrm{H}]^{+}\right)$; Anal. Calcd. for $\mathrm{C}_{58} \mathrm{H}_{62} \mathrm{Cl}_{2} \mathrm{FeGeSe}$ C, 67.15; H, 6.02. Found: C, 66.90; H, 6.16.

\subsubsection{Reaction of Chlorogermylenoid 4 with Tellurenylchloride $\mathbf{2 b}$}

A toluene solution $(3 \mathrm{~mL})$ of chlorogermylenoid $4(109.9 \mathrm{mg}, 0.154 \mathrm{mmol})$ was treated with $\operatorname{Trp} \mathrm{TeCl}(\mathbf{2 b}, 65.0 \mathrm{mg}, 0.156 \mathrm{mmol})$ at room temperature. After stirring the reaction mixture for $3 \mathrm{~h}$, 
the solvent was removed under reduced pressure. The residue was extracted into toluene and filtered before the solvent was removed from the filtrate under reduced pressure. The residue was purified by HPLC (eluent: toluene) and recrystallized from hexane to give $5 \mathbf{b}$ as the main product (58\% yield, $95.1 \mathrm{mg}, 0.0874 \mathrm{mmol})$ together with $6(17 \%, 16.0 \mathrm{mg}, 0.0126 \mathrm{mmol})$. Data for $5 \mathrm{~b}$ : orange crystals, m.p. $151{ }^{\circ} \mathrm{C}$ (dec.); ${ }^{1} \mathrm{H}$ NMR $\left(300 \mathrm{MHz}, \mathrm{C}_{6} \mathrm{D}_{6}\right.$, r.t.) $\delta(\mathrm{ppm}) 1.42(\mathrm{~s}, 36 \mathrm{H}), 4.62(\mathrm{~s}, 5 \mathrm{H}), 4.63(\mathrm{~s}, 2 \mathrm{H})$, $5.03(\mathrm{~s}, 1 \mathrm{H}), 6.67-6.72(\mathrm{~m}, 3 \mathrm{H}), 6.79-6.83(\mathrm{~m}, 3 \mathrm{H}), 7.01(\mathrm{~d}, 3 \mathrm{H}, J=7.1 \mathrm{~Hz}), 7.56(\mathrm{t}, 2 \mathrm{H}, J=1.7 \mathrm{~Hz}), 7.90(\mathrm{~d}$, $3 \mathrm{H}, J=7.3 \mathrm{~Hz}), 7.97(\mathrm{~d}, 4 \mathrm{H}, J=1.7 \mathrm{~Hz}) ;{ }^{13} \mathrm{C} \mathrm{NMR}\left(75 \mathrm{MHz}, \mathrm{C}_{6} \mathrm{D}_{6}, 298 \mathrm{~K}\right): \delta(\mathrm{ppm}) 31.71$ (q), 35.21 (s), 54.94 (d), 60.81 (s), 72.83 (d), 72.97 (d), 78.16 (s), 96.94 (s), 122.44 (d), 123.24 (d), 125.03 (d), 126.11 (d), 128.51 (d), 129.28 (d), 136.21 (s), 145.04 (s), 147.01 (s), 151.09 (s); ${ }^{125} \mathrm{Te} \mathrm{NMR}\left(94 \mathrm{MHz}, \mathrm{C}_{6} \mathrm{D}_{6}, 298 \mathrm{~K}\right)$ : $\delta$ (ppm) 244; MS (FAB): $m / z$ calcd. for $\mathrm{C}_{58} \mathrm{H}_{62}{ }^{37} \mathrm{Cl}_{2}{ }^{58} \mathrm{Fe}^{74} \mathrm{Ge}^{122} \mathrm{Te} 1086.1849\left([\mathrm{M}]^{+}\right.$), found 1086.1853 $\left([\mathrm{M}]^{+}\right)$; Anal. Calcd. for $\left[\mathrm{C}_{58} \mathrm{H}_{62} \mathrm{Cl}_{2} \mathrm{FeGeTe}+\mathrm{C}_{6} \mathrm{H}_{14}\right]$ : C, 65.57; H, 6.53. Found: C, 65.32; $\mathrm{H}, 6.66$.

\subsection{Computational Methods}

The level of theory and the basis sets used for the structural optimization are given in the main text. Frequency calculations confirmed minimum energies for all optimized structures. All calculations were carried out using the Gaussian 09 program package [15].

\subsection{X-ray Crystallographic Analyses}

Single crystals of [ $\mathbf{2} \mathbf{a} \cdot \mathbf{b e n z e n e}], \mathbf{2} \mathbf{b}, \mathbf{5} \mathbf{a}$, and $\mathbf{5 b}$ were obtained upon recrystallizations from benzene ([2a-benzene]) or hexane $(\mathbf{2} \mathbf{b}, \mathbf{5} \mathbf{a}$, and $\mathbf{5 b})$. Intensity data for [ $\mathbf{2} \mathbf{a} \cdot \mathbf{b e n z e n e}], \mathbf{5} \mathbf{a}$, and $\mathbf{5 b}$ were collected on a RIGAKU Saturn70 CCD system (RIGAKU, Tokyo, Japan) with VariMax Mo Optics using Mo $\mathrm{K} \alpha$ radiation $(\lambda=0.71073 \AA)$, while those for $\mathbf{2 b}$ were collected at the BL40XU beam line at Spring- 8 (JASRI, projects 2017A1647, 2017B1179, 2018A1167, and 2018A1405) on a Rigaku Saturn 724 CCD system (RIGAKU, Tokyo, Japan) using synchrotron radiation $(\lambda=0.7823 \AA)$. Crystal data are shown in the references. The structures were solved by direct methods (SHELXT-2014 [18]) and refined by a full-matrix least square method on $F^{2}$ for all reflections (SHELXL-2014 [19]). All hydrogen atoms were placed using AFIX instructions, while all other atoms were refined anisotropically. Supplementary crystallographic data were deposited at the Cambridge Crystallographic Data Centre (CCDC; under reference numbers 1846194-1846197 for [2a $\cdot \mathbf{b e n z e n e}$ ], $\mathbf{2 b}, \mathbf{5 a}$, and $\mathbf{5 b}$, respectively) and can be obtained free of charge via www.ccdc.cam.ac.uk/data_request.cif. Crystal data; [2a-benzene] $\left(\mathrm{C}_{26} \mathrm{H}_{19} \mathrm{ClSe}\right)$ : $M=445.82, \lambda=0.71073 \AA, T=-170{ }^{\circ} \mathrm{C}$, orthorhombic, $P b c a$ (no. 61), $a=10.3039$ (3) $\AA, b=18.5923(5)$ $\AA, c=21.1023(6) \AA, V=4042.6(2) \AA^{3}, Z=8, D_{\text {calc }}=1.465 \mathrm{~g} \mathrm{~cm}^{-3}, \mu=1.998 \mathrm{~mm}^{-1}, 2 \theta_{\max }=51.0^{\circ}$, measd. $/$ unique refls. $=33309 / 3943\left(R_{\text {int }}=0.0495\right)$, param $=253, \mathrm{GOF}=1.035, R_{1}=0.0279 / 0.0411$ [ $I>2 \sigma(I) /$ all data], $w R_{2}=0.0570 / 0.0615[I>2 \sigma(I) /$ all data], largest diff. peak and hole 0.341 and $-0.279 \mathrm{e} \cdot \AA^{-3}$ (CCDC-1846194); $2 \mathbf{b}\left(\mathrm{C}_{20} \mathrm{H}_{13} \mathrm{ClTe}\right): M=416.35, \lambda=0.7823 \AA, T=-180{ }^{\circ} \mathrm{C}$, monoclinic, $P 22_{1} / c$ (no. 14), $a=15.3100(3) \AA, b=8.0496(1) \AA, c=13.8261(3) \AA, \beta=115.690(3)^{\circ}$, $V=1535.49(6) \AA^{3}, Z=4, D_{\text {calc }}=1.801 \mathrm{~g} \cdot \mathrm{cm}^{-3}, \mu=2.690 \mathrm{~mm}^{-1}, 2 \theta_{\max }=56.0^{\circ}$, measd./unique refls. $=20016 / 4065\left(R_{\text {int }}=0.0676\right)$, param $=218$, GOF $=1.084, R_{1}=0.0483 / 0.0517[I>2 \sigma(I) /$ all data], $w R_{2}=0.1270 / 0.1284$ [ $I>2 \sigma(I) /$ all data], largest diff. peak and hole 2.241 and $-0.948 \mathrm{e} \cdot \AA^{-3}$ (CCDC-1846195); $5 \mathbf{a}\left(\mathrm{C}_{58} \mathrm{H}_{62} \mathrm{Cl}_{2} \mathrm{FeGeSe}\right): M=1037.37, \lambda=0.71073 \AA \mathrm{A}^{2} T=-170{ }^{\circ} \mathrm{C}$, triclinic, $P-1$ (no. 2), $a=9.3412(3) \AA, b=13.2993(7) \AA, c=21.3355(14) \AA, \alpha=93.977(4)^{\circ}, \beta=101.963(4)^{\circ}, \gamma=103.821(2)^{\circ}$, $V=2498.1(2) \AA^{3}, Z=2, D_{\text {calc }}=1.379 \mathrm{~g} \mathrm{~cm}^{-3}, \mu=1.765 \mathrm{~mm}^{-1}, 2 \theta_{\max }=53.0^{\circ}$, measd./unique refls. $=48637 / 10245\left(R_{\text {int }}=0.1265\right)$, param $=596, \mathrm{GOF}=1.136, R_{1}=0.0736 / 0.1313[I>2 \sigma(I) /$ all data], $w R_{2}=0.1431 / 0.1712\left[I>2 \sigma(I) /\right.$ all data], largest diff. peak and hole 0.831 and $-0.594 \mathrm{e} \cdot \AA^{-3}$ (CCDC-1846196); $\mathbf{5 b}\left(\mathrm{C}_{58} \mathrm{H}_{62} \mathrm{Cl}_{2} \mathrm{FeGeTe}\right): M=1086.01, \lambda=0.71073 \AA, T=-170{ }^{\circ} \mathrm{C}$, triclinic, $P-1$ (no. 2), $a=12.6102(6) \AA, b=15.3206(4) \AA, c=15.9034(7) \AA, \alpha=66.692(2)^{\circ}, \beta=68.112(2)^{\circ}, \gamma=71.139(3)^{\circ}$, $V=2562.03(19) \AA^{3}, Z=2, D_{\text {calc }}=1.408 \mathrm{~g} \mathrm{~cm}^{-3}, \mu=1.568 \mathrm{~mm}^{-1}, 2 \theta_{\max }=53.0^{\circ}$, measd. $/$ unique refls. $=29752 / 10195\left(R_{\text {int }}=0.0891\right)$, param $=632, \mathrm{GOF}=1.167, R_{1}=0.0680 / 0.1112[I>2 \sigma(I) /$ all data], $w R_{2}=0.1261 / 0.1487\left[I>2 \sigma(I) /\right.$ all data], largest diff. peak and hole 0.900 and $-0.851 \mathrm{e} \cdot \AA^{-3}$ (CCDC-1846197). 


\section{Conclusions}

Chalcogenyldichlorogermanes $\mathbf{5 a}$ and $\mathbf{5 b}$ were successfully synthesized from the reaction between an isolable ferrocenyl-substituted chlorogermylenoid and a sterically demanding ferrocenyl group ( $\left.\mathrm{Fc}^{*}\right)$. Ferrocenylchlorogermylenoid $\mathbf{4}$ is an appropriate precursor for the targeted ferrocenyl-substituted chalcogenyldichlorogermanes via nucleophilic reactions towards the sterically hindered chalcogenenyl chlorides. Thus, reactions of a halogermylenoid with a chalcogenenyl chloride represent an effective synthetic route to chalcogenyldichlorogermanes. Theoretical calculations showed that the $\mathrm{Ge}-\mathrm{Ch}$ bonds in these chalcogenyldichlorogermanes are strengthened due to $\mathrm{LP}(\mathrm{Ch}) \rightarrow \sigma^{*}(\mathrm{Ge}-\mathrm{Cl})$ interactions, suggesting promising potential for such chalcogenyldichlorogermanes as building blocks for organochalcogenylgermanes that bear a redox-active ferrocenyl moiety.

Supplementary Materials: The following are available online at http:/ /www.mdpi.com/2304-6740/6/3/68/s1, CIF and checkCIF files of complexes [ $2 \mathbf{a} \cdot \mathbf{b e n z e n e}], \mathbf{2} \mathbf{b}, \mathbf{5 a}$, and $\mathbf{5 b}$.

Author Contributions: T.S. (Takahiro Sasamori) conceived and designed the experiments; Y.S. and K.S. performed the experiments and measurements; N.T. provided laboratory space, access to machines, and financial support; T.S. (Takahiro Sasamori), Y.S., K.S., and T.S. (Tomohiro Sugahara) collected the chemical data and performed the XRD analyses; T.S. (Takahiro Sasamori) performed the theoretical calculations and wrote the manuscript.

Funding: This work was partially supported by a Grant-in-Aid for Scientific Research (B) 15H03777, a grant-in-aid for research at Nagoya City University, the Grant-in-Aid for Challenging Exploratory Research 15K13640, and the project of Integrated Research on Chemical Synthesis from the Japanese Ministry of Education, Culture, Sports, Science and Technology (MEXT).

Acknowledgments: We would like to thank Toshiaki Noda and Hideko Natsume at Nagoya University for the expert manufacturing of custom-tailored glassware. Y.S. and T.S. (Tomohiro Sugahara) would like to thank the Japan Society for the Promotion of Science (JSPS) for fellowships (JP15J00061 and JP16J05501).

Conflicts of Interest: The authors declare no conflict of interest.

\section{References}

1. Vaughn, D.D., II; Schaak, R.E. Synthesis, properties and applications of colloidal germanium and germanium-based nanomaterials. Chem. Soc. Rev. 2013, 42, 2861-2879. [CrossRef] [PubMed]

2. Kim, H.-S.; Jung, E.A.; Han, S.H.; Han, J.H.; Park, B.K.; Kim, C.G.; Chung, T.-M. Germanium Compounds Containing $\mathrm{Ge}=\mathrm{E}$ Double Bonds $(\mathrm{E}=\mathrm{S}, \mathrm{Se}, \mathrm{Te})$ as Single-Source Precursors for Germanium Chalcogenide Materials. Inorg. Chem. 2017, 56, 4084-4092. [CrossRef] [PubMed]

3. Sasamori, T.; Sakagami, M.; Niwa, M.; Sakai, H.; Furukawa, Y.; Tokitoh, N. Synthesis of a stable 1,2-bis(ferrocenyl)diphosphene. Chem. Commun. 2012, 48, 8562-8564. [CrossRef] [PubMed]

4. Sasamori, T.; Suzuki, Y.; Sakagami, M.; Miyake, H.; Tokitoh, N. Structure of stable telluradiphosphirane bearing bulky ferrocenyl ligands. Chem. Lett. 2014, 43, 1464-1466. [CrossRef]

5. Sasamori, T.; Suzuki, Y.; Tokitoh, N. Isolation and Structural Characterization of a Lewis Base-Free Monolithioferrocene. Organometallics 2014, 33, 6696-6699. [CrossRef]

6. Sakagami, M.; Sasamori, T.; Sakai, H.; Furukawa, Y.; Tokitoh, N. 1,2-Bis(ferrocenyl)dipnictenes: Bimetallic Systems with a Pn $=$ Pn Heavy $\pi$-Spacer (Pn: P, Sb, and Bi). Bull. Chem. Soc. Jpn. 2013, 86, 1132-1143. [CrossRef]

7. Suzuki, Y.; Sasamori, T.; Guo, J.-D.; Nagase, S.; Tokitoh, N. Isolation and Ambident Reactivity of a Chlorogermylenoid. Chem. Eur. J. 2016, 22, 13784-13788. [CrossRef] [PubMed]

8. Sasamori, T.; Sugamata, K.; Tokitoh, N. Halogenation reactions of a ditelluride having bulky aryl groups leading to the formation of organotellurium halides. Heteroat. Chem. 2011, 22, 405-411. [CrossRef]

9. Beckmann, J.; Hesse, M.; Poleschner, H.; Seppelt, K. Formation of mixed-valent aryltellurenyl halides $\mathrm{RX}_{2}$ TeTeR. Angew. Chem. Int. Ed. 2007, 46, 8277-8280. [CrossRef] [PubMed]

10. Beckmann, J.; Heitz, S.; Hesse, M. Four distinctively different decomposition pathways of metastable supermesityltellurium (IV) trichloride. Inorg. Chem. 2007, 46, 3275-3282. [CrossRef] [PubMed]

11. Ishii, A.; Matsubayashi, S.; Takahashi, T.; Nakayama, J. Preparation of a Selenenic Acid and Isolation of Selenoseleninates. J. Org. Chem. 1999, 64, 1084-1085. [CrossRef] 
12. Baker, R.J.; Jones, C. The molecular structure of ditriptycenyl ditelluride. Main Group Met. Chem. 2004, 27, 323-325. [CrossRef]

13. Yamaguchi, Y.; Nakata, N.; Ishii, A. Strong Solid-State Phosphorescence of 1,2-Telluraplatinacycles Incorporated into Rigid Dibenzobarrelene and Triptycene Skeletons. Eur. J. Inorg. Chem. 2013, 2013, 5233-5239. [CrossRef]

14. Suzuki, Y.; Sasamori, T.; Guo, J.-D.; Tokitoh, N. A Redox-Active Bis(ferrocenyl)germylene and Its Reactivity. Chem. Eur. J. 2018, 24, 364-368. [CrossRef] [PubMed]

15. Frisch, M.J.; Trucks, G.W.; Schlegel, H.B.; Scurseria, G.E.; Robb, M.A.; Cheeseman, J.R.; Scalmani, G.; Barone, V.; Mennucci, B.; Petersson, A.; et al. Gaussian09, revision E.01; Gaussian, Inc.: Wallingford, CT, USA, 2009.

16. Glendening, E.D.; Landis, C.R.; Weinhold, F. NBO 6.0: Natural bond orbital analysis program. J. Comp. Chem. 2013, 34, 1429-1437. [CrossRef] [PubMed]

17. Pangborn, A.B.; Giardello, M.A.; Grubbs, R.H.; Rosen, R.K.; Timmers, F.J. Safe and Convenient Procedure for Solvent Purification. Organometallics 2004, 15, 1518-1520. [CrossRef]

18. Sheldrick, G.M. SHELXT-Integrated space-group and crystal-structure determination. Acta Cryst. 2015, A71, 3-8. [CrossRef] [PubMed]

19. Sheldrick, G.M. A short history of SHELX. Acta Crystallogr. Sect. A 2008, 64, 112-122. [CrossRef] [PubMed]

(C) 2018 by the authors. Licensee MDPI, Basel, Switzerland. This article is an open access article distributed under the terms and conditions of the Creative Commons Attribution (CC BY) license (http:/ / creativecommons.org/licenses/by/4.0/). 